\title{
PERFORATED PEPTIC ULCER IN PARAPLEGIA
}

\author{
By Dr. J. J. Walsh, M.D., F.R.C.S., M.R.C.P., Mr. I. Nuseibeh, M.B., Ch.B.,
} L.M.S.S.A., F.R.C.S.Ed. and Dr. W. EL-MASRI, M.B., B.Chir.

National Spinal Injuries Centre, Stoke Mandeville Hospital, Aylesbury

IT is recognised that the diagnosis of diseases involving the gastro-intestinal tract can be a very difficult problem in paraplegic and tetraplegic patients (Wanebo \& Webb and Combs, I965; Inberg \& Prust, I968; Langenbach, 1969). This paper presents our experience of one particular abdominal emergency, namely, perforated peptic ulcer.

\section{MATERIAL}

There were ro patients, in whom a diagnosis of perforated peptic ulcer was made. The study covers a period from February I944 to January 1972. During this time 504I cases were treated in this Unit.

Nine patients were male and one was female. Eight patients were between 30 and 50 years of age and two patients between 25 and 30 .

Seven patients had a perforated duodenal ulcer and three patients had a perforated gastric ulcer. The duodenal perforations occurred from I to I I years after the onset of the paraplegia; while the gastric ulcer perforations occurred between 9 and 23 years after the onset. In other words, in this series duodenal perforations tended to occur at an earlier stage.

Diagnosis. In eight patients the condition was suspected on clinical grounds and out of these four were confirmed by laparotomy and had surgical treatment, whilst the remaining four were confirmed either by barium meal or plain abdominal $\mathrm{X}$-ray, and were treated conservatively. The mortality in all eight patients was nil. In two patients the condition was not diagnosed and both patients died after what was presumably inadequate conservative treatment (Table).

\section{TABLE}

\begin{tabular}{|c|c|c|c|c|c|c|c|c|}
\hline \multicolumn{2}{|c|}{ No. of patients } & \multicolumn{2}{|c|}{ Age-group } & \multicolumn{2}{|c|}{$\begin{array}{l}\text { Type of ulcer and } \\
\text { period post-paraplegia }\end{array}$} & \multirow{2}{*}{ Way of diagnosis } & \multirow{2}{*}{$\begin{array}{l}\text { Method of } \\
\text { treatment }\end{array}$} & \multirow{2}{*}{ Mortality } \\
\hline Male & Female & $25-30$ & $30-50$ & P.D.U. & P.G.U. & & & \\
\hline 9 & I & 2 & 8 & $\begin{array}{c}7 \\
\text { I-I I years }\end{array}$ & $\begin{array}{c}3 \\
9-23 \text { years }\end{array}$ & $\begin{array}{l}8 \text { patients were } \\
\text { clinically suspected } \\
\text { ( } 4 \text { confirmed by } \\
\text { laparotomy } \\
\text { the other } 4 \text { con- } \\
\text { firmed by either } \\
\text { plain X-ray } \\
\text { abdomen or } \\
\text { barium meal) } \\
2 \text { patients were } \\
\text { undiagnosed }\end{array}$ & $\begin{array}{l}\text { Conservative } \\
\text { Inadequate } \\
\text { conservative }\end{array}$ & $\begin{array}{c}\text { Nil } \\
\text { I00\% }\end{array}$ \\
\hline
\end{tabular}


In four cases the lesion was below $\mathrm{T}_{12}$ and these cases presented with the usual clinical picture of a perforation. Two of them were treated conservatively and the other two had surgical intervention. The other six patients were al lesions above $\mathrm{T}_{7}$, of which three were complete, and the other three were incomplete.

It was noticeable that the incompleteness, including sometimes extensive sensory sparing, did not appear to be of any great advantage in the diagnosis. We feel that the following case history gives a good illustration of the difficulties.

S. G. P. was a male patient, aged 3 I years, who before his accident had been a lorry driver. There was no relevant family history, but I month before his accident, he was discharged from hospital, following an appendicectomy with complications, which apparently required a second laparotomy over a total period of 6 months in hospital. There was no record of any indigestion.

At the age of 19 , in a diving accident, he sustained a fracture dislocation of $\mathrm{C}_{5} / 6$ and neurologically, he had a tetraplegia befow C6, which was at first complete. However, he made extensive sensory recovery before discharge from hospital. On discharge, light touch was present throughout, though there was some patchy hypoaesthesia. Although pain sensation was widely lost below $\mathrm{C}_{7}$, there was patchy hyperpathy on the right side of the body and patches of hypoalgesia on the left side.

Twelve years after his first discharge from hospital, the patient was admitted as an emergency. He stated that 12 hours previously he had a sudden onset of abdominal pain, with spasms, vomiting and also urinary retention. At that time he also had pain in both shoulders, more on the left than on the right, and stated that 2 days previously he had slight pain in the shoulders. On admission, he still complained of severe pain at the tip of the left shoulder, with a less marked pain at the tip of the right shoulder. His bowels had not been opened for 3 days, but this was not uncommon in his case. On examination, the patient was sweating profusely, had a subnormal temperature and a pulse of I20. The abdomen was soft with slight tenderness all over the right side. There were no bowel sounds but the abdomen was not distended. There was no release sign of peritonism, p.r. the rectum was empty but there was no ballooning.

An X-ray of the abdomen showed impacted faeces in the ascending colon but no free gas. Haemoglobin was 106 per cent., white cells 17,000 , and blood urea $38 \mathrm{mg}$. per cent. The bladder contained a small amount of very dirty urine. Intravenous fluids (i.e. normal saline alternating with Dextrose) was commenced. Eighteen hours later, the patient was still sweating profusely and then had almost continual abdominal spasms. Blood pressure was I60/I IO. The patient vomited once but the abdomen was still not distended. There were still no bowel sounds except on one single occasion when strong bowel sounds were heard. Intravenous fluids were continued and he was given $0.3 \mathrm{mg}$. of Prostigmine intramuscularly. A cystoscopy showed signs of chronic cystitis with some desquamation. At this stage it was considered that he had a urinary complication. Forty-eight hours after admission the haemoglobin was 83 per cent., white cells 15,000, and blood urea $59 \mathrm{mg}$. per cent. The patient said he felt better, temperature was $99^{\circ} \mathrm{F}$., pulse I IO. A further X-ray of the abdomen showed faeces in the splenic flexure, and a distended stomach. A stomach tube was passed and $18 \mathrm{oz}$. of stomach content aspirated. On the 4th day after admission the patient appeared very much better, but had developed diarrhoea. The stomach tube was removed and $\mathrm{II} / 4-\mathrm{Y}$ 
the patient began to take some fluids. Later, on the $5^{\text {th }}$ day after admission, his stomach again became distended and the Ryles tube was replaced. Although the patient maintained that he was feeling very much better, it was noticeable that he had very little sleep during the 5 days. On the 7 th day after admission the patient suddenly became very ill with blood pressure $80 / 60$, marked oliguria and a Ryles tube produced $44 \mathrm{oz}$. of light yellow fluid with some gas. Following this, his condition again improved and he appeared quite cheerful. However, at this stage, bowel sounds had again disappeared. On the 8th day after admission a laparotomy was carried out where it was found that the patient had an old standing generalised peritonitis with large collections of pus in the right paracolic area and a large left pelvic abscess. Three pints of blood-stained pus were removed, no perforation was seen and further exploration of the matted bowel was not considered advisable.

The abdomen was closed with drainage. The patient died about is minutes after return to the ward.

Post-mortem revealed that the patient had a perforated ulcer of the posterior wall of the stomach into the lesser sack.

This case is illustrative of the dangers involved in treating an undiagnosed perforation in a lesion above $\mathrm{T} 6$ or $\mathrm{T} 7$. Of the remaining three cases who were operated on, an important indication in all three was referred pain at the shoulder tip.

Of the cases treated conservatively, their general condition and progress, under close clinical supervision, was considered adequate treatment at a time when conservative treatment of perforated peptic ulcers was being widely practised.

\section{DISCUSSION}

It is interesting that both the fatal cases occurred in the first 12 years of the Unit's existence. It is perhaps reassuring that no further fatalities have occurred amongst the remaining eight cases.

One of the authors (I. N.) has noted that the majority of cases were experienced paraplegics, every one of whom reported with a complaint of being very ill. Their complaint was notably more definite than in other patients with acute urinary flare-ups or other urinary complications. Poor documentation does not allow us to give accurate numbers but the great majority in our memory (J. J. W.) complained of shoulder tip pain. Only three patients on admission to hospital as emergencies were obviously shocked. In addition, those patients who had apparently been shocked in the early stages, at home or in another hospital, frequently went through a period when they appeared to be recovering and subjectively felt better. As illustrated in the case history given, increased spasms of the abdominal muscles in a high lesion is an important sign. Abdominal pain and particularly peritoneal irritation and tenderness is not always a reliable sign even in low lesions. This is hard to understand. Increased tone of the abdominal muscles on one side, as compared with the other and rather different from the normal board-like rigidity which one sees in a non-paraplegic patient, is an important sign. Eight patients had nausea and vomiting. Since urinary complications are more common in paraplegics than any other patients, this must be carefully excluded as a cause of the signs and symptoms, before establishing the diagnosis of an abdominal emergency. Nowadays the more easy availability of suitable 
investigations, including intravenous pyelogram, is a helpful factor in excluding ureteric obstruction.

In our experience the following findings are of immense importance in making the diagnosis of a perforated ulcer.

(I) The patient, if, as is usual, is an experienced paraplegic, will complain of feeling very ill. Sometimes out of proportion to his physical signs.

(2) The patient has complained of nausea and vomiting.

(3) Increased tone especially in the abdominal muscles.

(4) Increased sweating.

(5) Absent bowel sounds.

(6) A previous history indicative of peptic ulceration.

(7) Insomnia during the period after the onset of the complication.

We would like to stress the importance of a straight X-ray of the abdomen in the erect position as well as supine.

A marked increase in the white cell count some 12 hours or more after the onset of the emergency is indicative, but it must be remembered that this is also very common indeed in urinary complications.

Diarrhoea and increased blood urea are rather late manifestations and of grave prognosis.

As so often occurs in paraplegia, some patients will inevitably have a history of so-called 'root pain', perhaps for many years. Such a previous history can make the diagnosis even more difficult. Finally, we would like to stress once again, that shoulder-tip pain, coming on suddenly in a high lesion some years after injury, is the most important physical sign.

\section{REFERENCES}

Inberg, H. O. \& Prust, F. W. (I968). Arch. Phys. Med. E Rehab. 49, 343.

LANGENBACK, R. J. (1969). Gastro-intestinal problems. In Spinal Cord Injuries, ed. by D. Ruge, pp. II 5-I I 7. Springfield, Illinois: Charles C. Thomas (I969).

Wanebo, H. J., WebB, E. \& Combs, R. (1965). California Medicine, ro3, I93. 